\title{
RESULTS OF PRIMARY RETINAL REATTACHMENT SURGERY: A PROSPECTIVE AUDIT
}

\author{
P. M. SULLIVAN ${ }^{1}$, A. J. LUFF ${ }^{2}$ and G. W. AYLWARD ${ }^{1}$ \\ London and Southampton
}

\begin{abstract}
SUMMARY
Purpose: To define the current success rate of primary retinal detachment repair at one centre.

Methods: One hundred and fifty-three consecutive patients undergoing surgery for primary retinal detachments over a 6 month period were studied prospectively. Data sheets were completed immediately after surgery and at final follow-up. One hundred and twenty-seven patients completed 6 months of followup. Follow-up data on the remainder were obtained from the referring unit or directly from the patients by telephone. The term primary success was used to describe persisting retinal reattachment after a single operation. Multiple logistic regression was carried out to establish factors associated with failure.

Results: One hundred and twenty-three patients $(80 \%)$ had persisting retinal reattachment after a single procedure. Of the 30 patients who required further surgery, in 5 the retina remained detached at final follow-up. The final anatomical success rate was $97 \%$. New or missed breaks were the major causes of failure of primary surgery. Failure of primary surgery was associated with the presence of highly elevated breaks $(\beta=0.11, p=0.03)$. No other pre-operative factors appeared to predict failure to reattach the retina.

Conclusions: Comparison of these results with those of a previous audit carried out at this hospital 23 years ago suggests little improvement in the success rate of primary surgery $(\mathbf{7 5} \%$ vs $80 \%)$. The improvement in final retinal reattachment has been rather greater (from $88 \%$ to $97 \%$ ). The major impact of recent technical advances in retinal reattachment surgery has been on the success rate of reoperations after failed primary surgery.
\end{abstract}

Over half a century ago Gonin ${ }^{1}$ reported the first large series of successful treatment of rhegmatogen-

From: ${ }^{1}$ The Vitreoretinal Unit, Moorfields Eye Hospital, London; ${ }^{2}$ The Eye Unit, Southampton General Hospital, Southampton, UK.

Correspondence to: Paul Sullivan, Moorfields Eye Hospital, City Road, London EC1V 2PD, UK. Tel: (+44) 01712533411. Fax: (+44) 01712534696. ous retinal detachment. Subsequent development of new techniques, and in particular the introduction of indirect ophthalmoscopy, cryotherapy and scleral buckling, resulted in a steady improvement in the results of surgery. ${ }^{2}$

The last published audit from this hospital reported a primary success rate of $75 \%{ }^{3}$ Since that time there have been further advances in vitreoretinal surgery. Techniques of pars plana vitrectomy have become more refined, with the introduction of fluid-gas exchange, long-acting intraocular gases, ${ }^{4}$ endolaser and indirect laser retinopexy, perfluorocarbon liquids ${ }^{5}$ and the resurgence in the use of silicone oil. ${ }^{6}$ As a result many primary retinal detachments are now managed using an internal approach. ${ }^{7,8}$ In the light of these developments we decided to prospectively re-evaluate the results of primary retinal detachment repair.

\section{SUBJECTS AND METHODS}

All rhegmatogenous retinal detachments undergoing primary retinal reattachment surgery at Moorfields Eye Hospital over a 6 month period were included. All surgery was carried out by the registrars, senior registrars, fellows and consultants of the vitreoretinal unit.

An internal approach was used in eyes with posterior retinal breaks, media opacities hindering the view, giant retinal tears or proliferative vitreoretinopathy sufficient to prevent closure of breaks by conventional surgery. An internal approach was also adopted in some eyes with bullous retinal detachments with superior retinal tears. ${ }^{7}$ Otherwise a conventional approach was employed using cryotherapy with an explant, supplemented by drainage of subretinal fluid and intravitreal air injection as necessary.

Two data sheets were completed on each patient: one at the time of primary surgery and one at the 6 month or final follow-up visit. Twenty-six patients were discharged before 6 months of follow-up. Their 
Table I. Patient characteristics at presentation

\begin{tabular}{lrr}
\hline Characteristic & No. & $(\%)$ \\
\hline Macula attached & 63 & $(41)$ \\
Phakic & 112 & $(73)$ \\
$>6$ D myopia & 32 & $(21)$ \\
Single retinal breaks & 70 & $(45)$ \\
Posterior retinal breaks $^{\text {a }}$ & 30 & $(20)$ \\
Inferior retinal breaks $^{\mathrm{b}}$ & 60 & $(39)$ \\
\hline
\end{tabular}

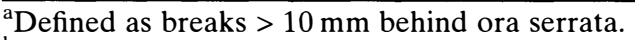

${ }^{b}$ Breaks in the inferior 4 clock-hours.

status at 6 months was determined by contacting the referring unit. Patients who had been discharged were also contacted by telephone. In the absence of any history of retinal surgery at another hospital or deterioration in vision it was assumed that the retina remained attached.

In this way 75 items of data were recorded on each patient. These data were entered onto a database (Filemaker Pro 2.1, Claris) that was used for primary data analysis. Multiple stepwise logistic regression, to determine factors associated with failure, was performed on a statistical software package (SPSS, SPSS Inc.).

\section{RESULTS}

One hundred and fifty-three patients were included in the audit. The median age was 52 years (range 8-85 years). Table I shows the characteristics of the patients at presentation. One hundred and one patients underwent conventional (i.e. non-vitrectomy) repair, of whom 59 required drainage of subretinal fluid and 41 injection of air or gas. Fiftytwo patients had primary vitrectomies with internal tamponade. The overall rate of retinal reattachment after one operation was $80 \%$. The majority of

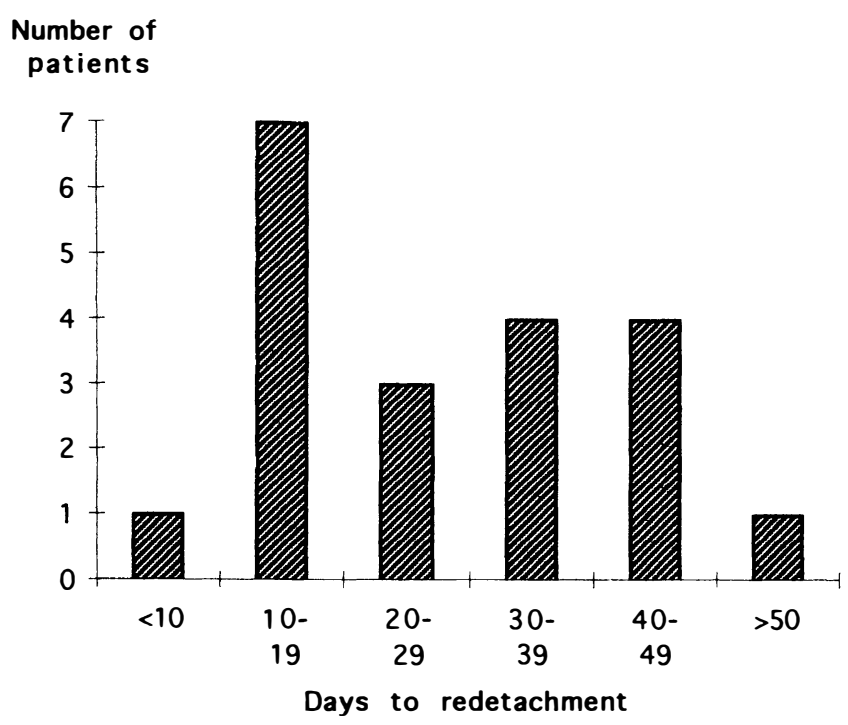

Fig. 1. Time in days from surgery to redetachment in 20 patients in whom this could be accurately established.
Table II. Per-operative complications and anatomical outcome

\begin{tabular}{ll}
\hline Procedure & No. of patients \\
\hline Conventional procedures & $(n=101)$ \\
Haemorrhage at drain site & $2(2 \%)$ \\
Inadvertent drainage of subretinal fluid & $5(5 \%)^{\mathrm{a}}$ \\
Retinal incarceration & $2(2 \%)^{\mathrm{a}}$ \\
Drainage retinotomy & $4(4 \%)$ \\
Vitrectomy & $(n=52)$ \\
Lens touch & $2(4 \%)$ \\
Choroidal haemorrhage & $3(3 \%)$ \\
Inadvertent retinotomy & $5(5 \%)$
\end{tabular}

ancluding a case of both drain and incarceration in a single patient.

redetachments occurred in the first 7 weeks after surgery (Fig. 1).

Five patients still had retinal detachments at the end of follow-up and in none of these patients was further surgery deemed appropriate. One had suffered a massive suprachoroidal haemorrhage at the time of primary vitrectomy. The other 4 patients had extensive proliferative vitreoretinopathy (PVR) and were deemed inoperable.

Operative and post-operative complications are shown in Tables II and III. The reasons for failure of primary surgery are shown Fig. 2. The visual outcome is illustrated in Fig. 3. Using multiple logistic regression analysis, pre-operative factors that predicted poor final vision were poor vision at presentation $(\beta=-0.26, p=0.02)$ and myopia $(\beta=0.11, p=0.03)$. Failure of primary surgery was associated with presence of elevated breaks (defined as breaks not closeable on indentation) $(\beta=-0.19$, $p=0.04)$. Other factors including age, presence of inferior breaks, phakic status and grade of surgeon exerted no significant effect on the visual or anatomical outcome when these were taken into account.

\section{CONCLUSIONS}

While retinal reattachment is the immediate objective of retinal reattachment surgery the ultimate goal is maintenance or restoration of visual function. The results presented here may underestimate final visual function, given that the follow-up period was 6 months and visual function continues to improve a year after macular reattachment. ${ }^{9}$

Comparison of these results with those of the previous audit ${ }^{3}$ does not suggest $\cdot$ a statistically significant increase in the success rate at this hospital

Table III. Post-operative complications

\begin{tabular}{lcc}
\hline & No. of patients (\%) \\
\hline Diplopia & 5 & $(3 \%)$ \\
Distortion & 2 & $(1 \%)$ \\
Choroidal haemorrhage & 3 & $(2 \%)$ \\
Corneal abrasion & 7 & $(5 \%)$ \\
Raised intraocular pressure & 15 & $(10 \%)$ \\
Epiretinal membrane & 3 & $(2 \%)$ \\
\hline
\end{tabular}




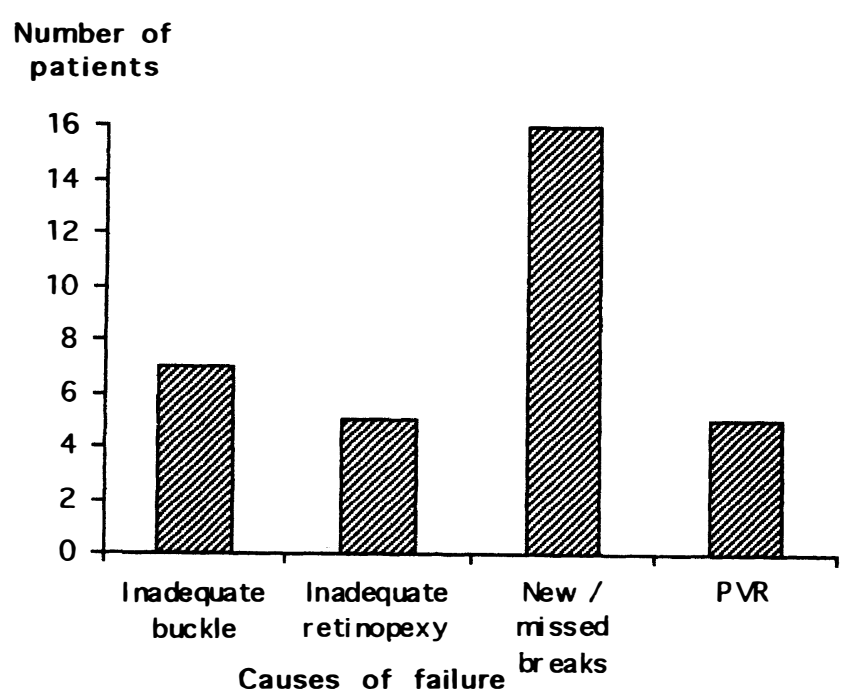

Fig. 2. Reasons for failure after primary retinal detachment repair. (NB: the groups are not exclusive.)

over the last 23 years. Since both this and the previous Moorfields audit only studied cases that were operated on, selection bias could be present through the refusal of some patients for surgery. There have been greater advances in the management of more complex cases in which primary surgery has failed, as shown by the number of persistent detachments at final follow-up (3\% in the current audit compared with $12 \%$ in the previous study). ${ }^{3}$

Although PVR was the commonest cause of final failure to reattach the retina, avoidable factors such as inadequate buckles and inadequate retinopexy were significant in failure of primary surgery. We are conducting an interim case note review of failed retinal detachment procedures and regular critical incident audits to reduce the incidence of these avoidable factors and thereby improve our primary success rate. A future audit using a similar design to the one reported here will then be carried out to determine whether these measures have any effect, thus completing a clinical audit cycle. The lack of an apparent association between the grade of the surgeon and the success rate presumably reflects the tendency for more junior surgeons to manage more straightforward detachments.

Success rates of the order of $75-80 \%$ retinal reattachment after a single procedure have been reported over the last few years from several units (A. Laidlaw and S. Ruben, personal communications, and McGalliard ${ }^{10}$ ). While comparisons of the results between units are difficult because of variations in the case mix of patients, the broad agreement between these success rates is striking and suggests that a primary surgical success rate of $75 \%$ is a

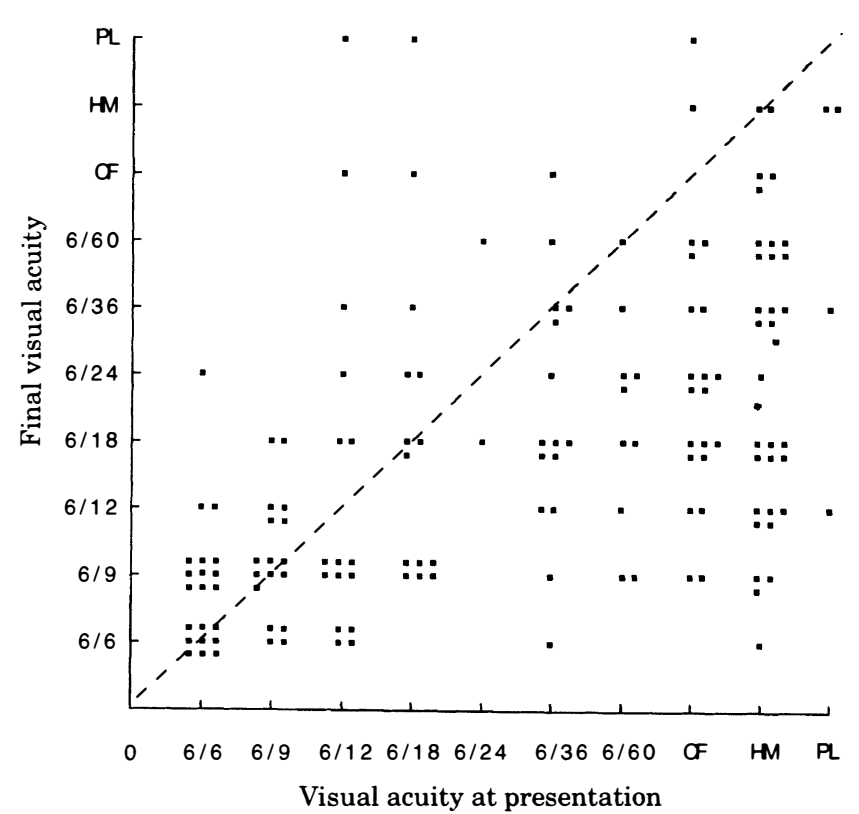

Fig. 3. Visual outcome at final follow-up after retinal reattachment surgery.

reasonable goal and standard for future audits. Such periodic prospective audit, with implementation of measures to address any deficiencies in patient care that these bring to light, remains the best way for clinicians to monitor the quality of care they offer to patients with retinal detachments.

\section{REFERENCES}

1. Gonin J. Le décollement de la rètine: pathogénietraitement. Lausanne: Libraire Payot, 1934.

2. Tasman W. History of retina 1896-1996. Ophthalmology 1996;103(Suppl):143-51.

3. Chignell AH, Fison LG, Davies EWG, Hartley RE, Grundy MF. Failure in retinal detachment surgery. $\mathrm{Br}$ J Ophthalmol 1973;57:525-30.

4. Norton EWD. Intraocular gas in the management of selected retinal detachments. Trans Am Acad Ophthalmol 1973;77:85-98.

5. Chang S. Low viscosity fluorochemicals in vitreous surgery. Am J Ophthalmol 1987;103:38-43.

6. Scott JD. A rationale for the use of liquid silicone. Trans Ophthalmol Soc UK 1977;97:235-7.

7. Hakin KN, Lavin MJ, Leaver PK. Primary vitrectomy for rhegmatogenous retinal detachment. Graefes Arch Clin Exp Ophthalmol 1993;231:344-6.

8. Gartry DS, Chignell AH, Franks WA, Wong D. Pars plana vitrectomy for the treatment of rhegmatogenous retinal detachments uncomplicated by advanced proliferative vitreoretinopathy. $\mathrm{Br} \mathrm{J}$ Ophthalmol 1973; 77:199-203.

9. Chisholm IA, McClure E, Foulds WS. Functional recovery of the retina after retinal detachment. Trans Ophthalmol Soc UK 1975;95:167-72.

10. McGalliard J. Audit of retinal detachment surgery. Presented at the Britain and Eire Association of Vitreoretinal Surgeons meeting, Bristol, October 1994. 